\title{
Susane, a device for sampling chemical gradients in the benthic water column
}

\author{
Knoery Joël ${ }^{1,}{ }^{*}$, Cossa Daniel ${ }^{2,3}$, Thomas Bastien ${ }^{1}$, Germain Gregory ${ }^{4}$, Rigaud Sylvain 5
}

${ }^{1}$ Dépt. RBE/BE/LBCM,IFREMER Nantes F,rance

2 Dépt. ODE/UL/LERPAC,IFREMER La Seyne sur Mer ,France

${ }^{3}$ ISTerre,Université de Grenoble Alpes Grenoble Cedex 9 ,France

${ }^{4}$ Dépt. REM/RDT/LCSM,IFREMER Boulogne-sur-Mer ,France

${ }^{5}$ EA 7352 CHROME,Université de Nîmes Nîmes, France

* Corresponding author : Joël Knoery, email address : knoery@ifremer.fr

\begin{abstract}
:
In aquatic environments, the benthic water column exhibits strong concentration gradients of various substances. They result from transfers and chemical reactions that may occur both within this layer, and at the sediment-water interface (SWI). Characterization of these gradients yields important information for the quantification of such processes and transfers. However, it is difficult to actually sample these gradients in the field, since turbulence decreases their vertical scale. This article describes a sampler designed to collect simultaneously 16 discrete water column samples at a centimeter-scale vertical resolution. This small device $(40 \times 40 \times 60 \mathrm{~cm})$ is reliable, safe to handle, and easily deployed from a small boat using a cable or a Scuba diver. It is made of materials compatible with trace element and dissolved gases work, and simultaneously draws samples from various heights above the SWI into $60 \mathrm{~mL}$ syringes. The altitude of the sample inlets is field-adjustable. Sampling artifacts are minimized by in situ flushing of tubing dead volumes, by rapid and simultaneous sample collection, and by sampling an undisturbed water-column. Thus, this device can contribute to the characterization of vertical concentration gradients in benthic water-columns. Such gradients of various compounds and metals from two coastal sites (Quiberon Bay and Berre Lagoon) are shown, illustrating the sampler's usefulness to describe and investigate processes in the benthic zone.
\end{abstract}




\section{Introduction}

Surficial sediments play an important role in redistributing reactive substances delivered to the sea-floor by particles settling from the overlying water-column. Within surficial sediments, the decomposing organic matter enriches its surrounding porewaters and overlying water with dissolved species. The quantification of rates and direction of these chemical exchanges is crucial to better constrain sedimentary budgets and processes, in particular at the sediment waterinterface (SWI). For this purpose, estimations can be derived from vertical profiles of dissolved chemicals on either side of the SWI (e.g., Berner, 1980; Schulz, 2000; Dade et al., 2001), even if chemical gradients on either side of the SWI may greatly vary over time and space due variabilities of reaction and transport processes.

Within sediment porewaters, chemical gradients may occur at the sub-millimeter scale, because of the relatively reduced mixing rates (mainly molecular diffusion and bioturbation), and because of spatial heterogeneities in the geochemistry and biology of sediments. Turbulent diffusion is a main contributor to mixing within the water-column, where vertical chemical gradients may be observed at the sub-millimeter scale (e.g., in diffusive boundary layers with their low turbulent diffusion rates) or at the meter scale (e.g., mid-water pycnoclines). Compared to porewaters, the much larger mixing rates of the benthic water column are expected to average vertical gradients resulting from reactions and transfers at the SWI. Also, chemical gradients observed at one location in the water column result from processes occurring over a wider horizontal area. Furthermore and particularly in shallow environments, rates of processes at the SWI may be very temporally variable, because of the diversity and variability of organic matter sources and their spatial distribution controlled by sedimentary hydrodynamics. Thus, to obtain a quantitative representation of such environments and ultimately better quantify chemical exchanges at the 
SWI, the acquisition of water-column samples in the benthic zone at appropriately high spatial and temporal resolutions has to be feasible.

The capture of such gradients requires specifically designed high-resolution sensors and samplers. This challenge has long been met for electrochemically and optically reactive species that can be determined in situ using specifically designed microsensors (i.e., potentiometric or amperometric sensors for $\mathrm{pH}, \mathrm{O}_{2}$, and $\mathrm{H}_{2} \mathrm{~S}$ ). Commercially available sensors (e.g., Unisense) can be used in the diffusive boundary layer, less than one centimeter above the sediment (e.g., Glud, 2008). Unfortunately, sensors are unavailable for most chemical substances, and hence discrete water samples for ex situ analyses still have to be collected at the adequate vertical resolution in order to describe benthic chemical gradients. Several devices already exist to fill this need. Bale and Barrett (1995) designed a device to characterize suspended matter and phytoplankton; it collects up to ten discrete, $4 \mathrm{~L}$ samples in the first two meters above the SWI. Likewise, Thomsen et al. (1994) devised an instrument cage about $2 \mathrm{~m}$ high and $3 \mathrm{~m}$ wide which can pump $15 \mathrm{~L}$ of water at up to four heights within the first meter of the water column. More recently, a device able to collect 12 samples in the bottom $2 \mathrm{~m}$ of water column for deep marine environments was developed by Sauter et al. (2005) and subsequently improved by Holtappels et al. (2011). Nevertheless, the size of these samplers precludes their use from a small craft, and consequently in near-shore environments.

To describe gradients occurring in the coastal, benthic water-column, we developed a lightweight and low-cost System for Underwater SAmpling of beNthic Environments. The device nicknamed SUSANE can simultaneously collect up to 16 water samples. We detail here its design features, its experimental validation, and show examples of vertical profiles of dissolved chemical species in the benthic water-column. Its vertical resolution allowed to capture concentration gradients of various major and trace elements in the benthic water columns of an 
open bay and a lagoon. The results demonstrate that production and consumption processes of such substances in the benthic layer do support such concentration gradients, despite turbulent mixing which tends to eliminate them. While the gradients' presence may be inferred from modelling studies (e.g., Pakhomova et al., 2018), tools like SUSANE are helpful for their direct observation because they can collect the appropriate discrete samples. In the future, coupling such observations with hydrodynamics of the benthic layer will contribute to a better understanding of their biogeochemical fluxes near the SWI.

\section{Materials and procedures}

\section{Design features and description}

A schematic of the device is shown in Fig. 1 with a 40x40x60cm syringe module comprising the syringe holder and its spring-loaded, telescopic jack and a vertical mast supporting sampling inlets. Its two grey, parallel PVC plates are machined to fit syringe barrels and pistons. They are pushed apart when the knee-joint lock is released using a trigger. It operates similarly to locking pliers whose release is easily obtained with a slight force applied to a secondary lever, despite the possibly strongly clenched jaws. This trigger brings safety and reliability to SUSANE, which is an important consideration when the compressed spring of the jack stores a recoil force of $500 \mathrm{~N}$. 


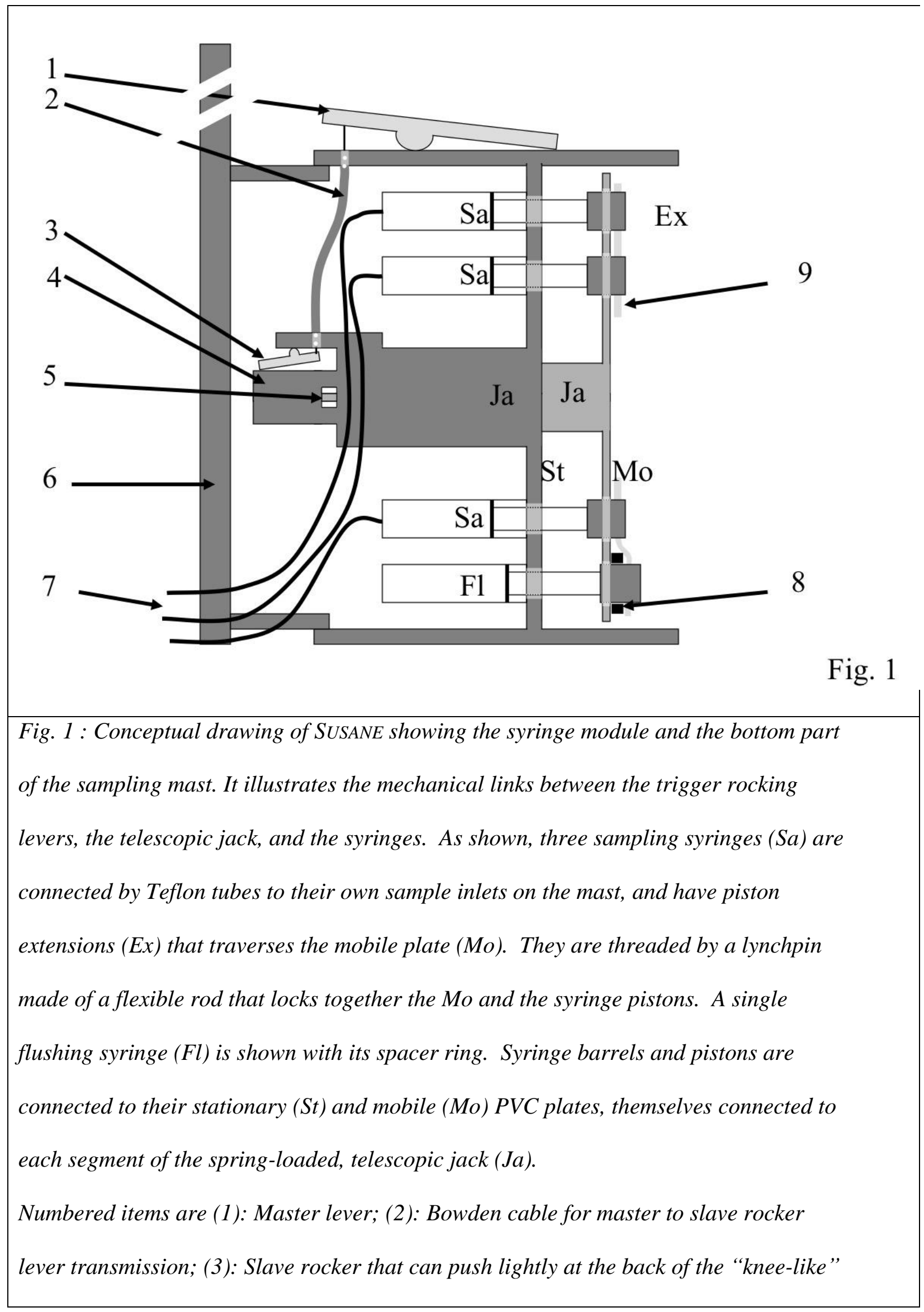


hinge; (4): Knee-like hinge that locks when overextended in its open position; (5):

Smooth stainless steel rod connecting the distal end of the hinge and the mobile plate. It maintains the mobile plate and the compressed spring when in the hinge is extended;

(6): Sampling mast supporting the 16 sampling tube inlets at their chosen positions; (7):

Example of three sampling tube inlets near the base of the mast with the rest of the

flushing manifold omitted for clarity; (8): a 20mm high spacer ring to take up the play

between lynchpin and mobile plate; (9): flexible rod threaded through all the piston

extensions.

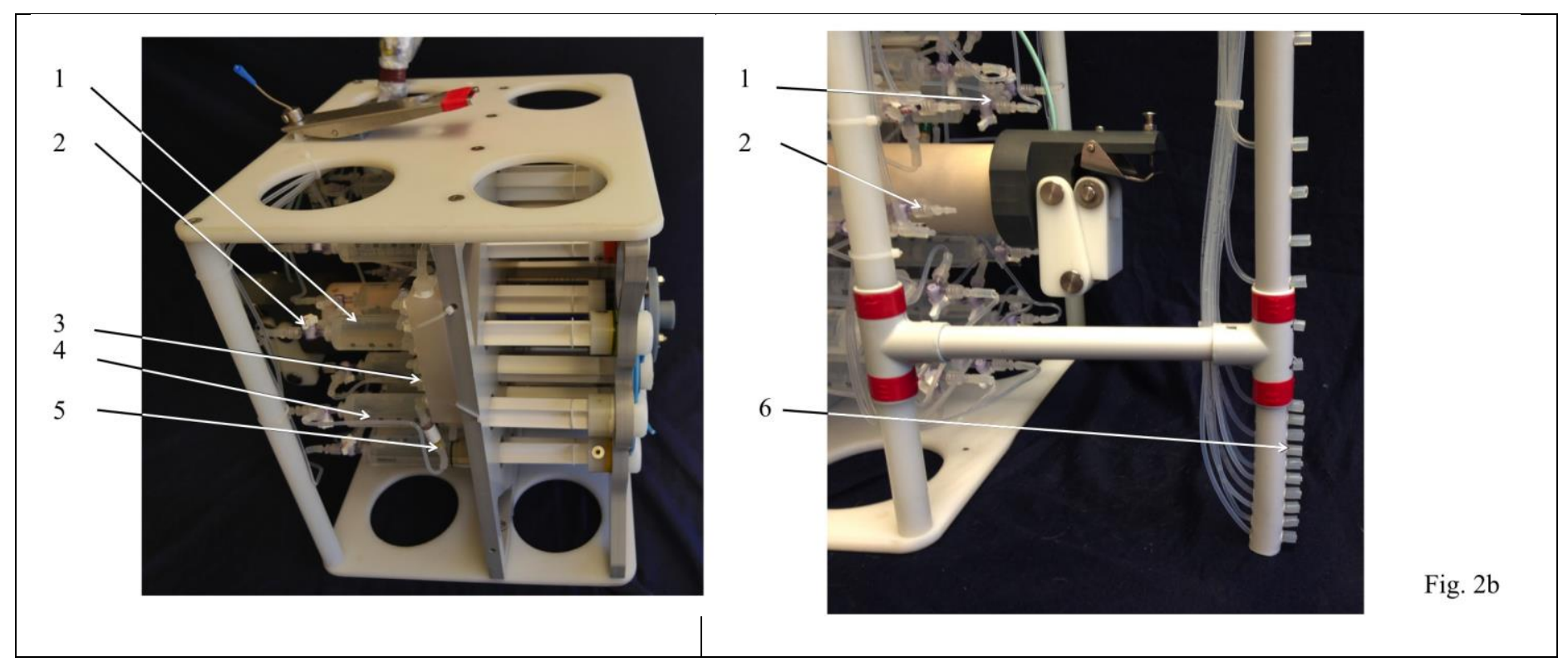




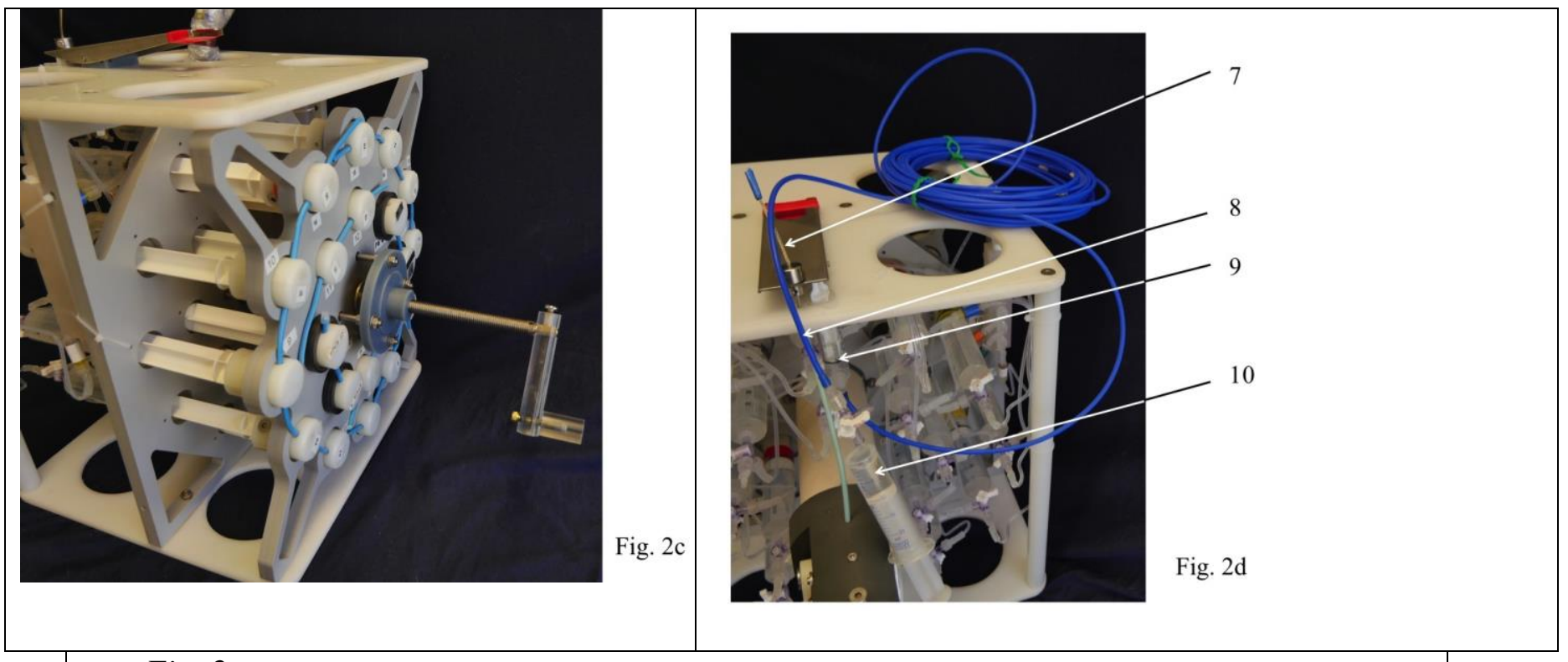

Fig. 2

Panels $a, b, c$ : Side and rear photographs of the SUSANE in its tripped position (i.e., bent hinge). To show the inner workings of SUSANE, its two flat fairing plates that act as vanes have been removed from the sides of the device (panels a and c). Except for the hinge and its sampling mast which is $180 \mathrm{~cm}$-high and offset from its main body by 20cm, SUSANE main body's dimensions shown in Panel (a) are $40 \times 40 \times 40 \mathrm{~cm}$. Panel a: (1): Filled sampling syringe; (2): its 3-way valve ; (3): flushing manifold; (4): flushing tubing along a sampling syringe; (5): check-valve.

Panel b: (6): for scale and to illustrate the sampling resolution of SUSANE, the lowest sample inlets in the vertical mast are 10mm apart. The vertical resolution can be adjusted in the field by moving the sampling tubes to other pre-drilled positions elsewhere on the mast. In the picture, the mast is offset by $20 \mathrm{~cm}$ from the lower edge of syringe module.

Panel c: three black spacer rings around extensions of the flushing syringes pistons are visible, the cocking screw and its removable crank are used to compress the 
spring inside the jack, the lynchpin (blue polymer rod), and the red-tipped master rocker lever on the top of SUSANE.

Panel d: (7): Bowden cable linking master and slave rockers; (8): 20meters of waterfilled, semi rigid tubing coiled and terminated by the master and slave syringes; (9): slave syringe whose piston extends upward to actuate the master rocker, when the piston of the master syringe (10) is pushed in by the operator.

\section{Description and operation of the trigger and telescopic jacks}

Below is the description and functioning of the mechanisms comprised in the lock and release, and in the jack. It begins by the knee-like hinge that controls the recoil of the spring, and its trigger to easily release it (Fig. 1). The hinge functions similar to a human knee that locks when over-extended while supporting the weight of its owner. It is completed by a smooth stainless steel rod that connects the distal part of the hinge (its "ankle") to the mobile PVC plate, passing through the center of the coil spring. The rod and hinge lengths are adjusted so that the hinge angle is $180^{\circ}$ when the coil spring is at maximum compression, i.e., the two PVC plates are in contact. When readying SUSANE, slight push on the front of the "knee" overextends it, and opens the hinge to its maximum angle, $183^{\circ}$ by construction. At this point, the hinge and spring are reliably locked.

To trigger SuSANE, the hinge is closed by a slight push from one arm of a "slave" rocking lever (rocker) applied to the back of the "knee". This rocker is mechanically paired to a "master rocker" using a short Bowden cable. There are two ways to trigger sampling : pushing on the master rocker using either a syringe piston (preferred), or impact of an oceanographic messenger (alternate). 
To use a messenger as a trigger, SUSANE is suspended with a line along which the messenger will slide and hit the raised arm of the master rocker. When pushed down by the messenger's impact, the lever's other arm pulls on the Bowden cable. In turn, this rotates the slave rocker which pushes at the back of the knee-like hinge to trigger SUSANE. Instead of messenger impact, force can also be applied remotely on the master rocker using a simple hydraulic system. For this purpose two syringes are half-filled with water and connected at both ends of a length of a waterfilled $2 \mathrm{~mm}$ ID semi-rigid tubing. The master syringe is held in hand, and the slave syringe is mounted on SUSANE, with its piston protruding under the master rocker (see Fig. 2d). To trigger SUSANE, the operator pushes in the piston of the master syringe, which makes the slave piston slide out and push up the master rocker. This procedure can be used equally well to trigger SUSANE remotely either from a small boat or by a SCUBA diver.

The telescopic jack compresses a coil spring held in two, concentric and rigid PVC pipe segments. A stationary plate holding the syringe barrels is welded to the non-mobile outer pipe, while another mobile plate is welded to the inner pipe that slides out. The small lateral play between the concentric pipes maintains the plates parallel during the telescoping, to ensure that the syringes fill at the same rate. 

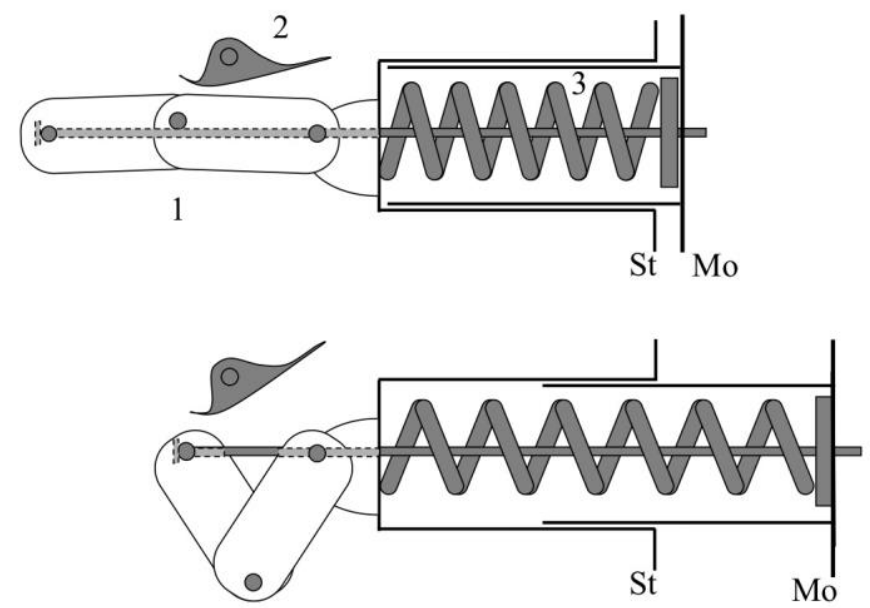

Fig. 3

Fig. 3: Schematic of the telescopic jack functionning in SUSANE before and after triggering. Top panel: the jack is in a cocked position and ready to be tripped. (1) Knee joint-like hinge in its overextended, locked position. Rotation of slave rocker (2) pushes its left end on the "back" of the knee-joint, decreasing its angle to less than $180^{\circ}$, at which point the force of the coil spring (3) finishes to bend the kneelike hinge. Bottom panel: the hinge has bent and allowed the smooth stainless steel rod to move rightward, and the jack to extend, thus pushing the mobile plate (Mo) apart from its stationary counterpart (St).

Syringes and the plates

The syringe barrels are bayonet-locked by their finger rests. The finger-rests are placed within matching hollowed-out ovals that are milled within the $10 \mathrm{~mm}$ thickness of the stationary PVC plate, and then twisted into side rabbets, also machined in the ovals. The web of tubes between the 20 syringe canulae prevents the barrels from twisting back and out of their locked-in positions. 
Each syringe piston is fitted with a cylindrical, drilled extension which protrudes through the 20 circular openings machined in the mobile plate. A flexible rod is threaded through every extension's hole to act as an easily removable lynchpin. The push of the PVC plate is actually exerted on the pin, which pulls the extensions and draws out the syringe pistons. Importantly, the extension hole is drilled so that the locking pin traverses each extension exactly $20 \mathrm{~mm}$ from the mobile plate at its rest, in cocked position (i.e., when the jack is fully compressed). This "travel play" and its elimination by $20 \mathrm{~mm}$-high rings around the flushing syringe extensions differentiate them from the sampling syringes.

\section{Configuration and functioning of manifold for flushing dead volumes}

The most innovative feature of SUSANE is the elimination of virtually all dead volume in the collected samples, despite the variable lengths of tubing placed between syringes and sample inlets. For this purpose, a tube network has been designed to take advantage of an initial flushing stage at the beginning of the stroke of the mobile PVC plate. Each of the 16 sampling syringes is fitted with a 3-way/2-position, Luer-Lock valves, and the two remaining ports of the valves are connected to two $1.5 \mathrm{~mm}$ inner diameter (ID) Teflon tubes. The first tube draws sample from the chosen sample height above the sediment (Fig. 4). The second tube is used to draw dead-volume and its second end is connected one of the flushing manifolds through a Luer-Lock check-valve. All the flushing syringes fill by drawing liquid through the flushing manifolds and the checkvalves prevent any unintended back-flow into the sampling syringes. To assemble this tube network, the rigid, Teflon tube ends are sleeved with $4 \mathrm{~cm}$ lengths of $1 \mathrm{~mm}$ ID x 5mm OD silicone tubing. This enables to use inexpensive polyethylene barbed fittings and Luer adaptors throughout. 
The tubing network functions as follows. The flushing syringes have no travel "play" between the mobile PVC plate and the lynchpin rod, because of their 20mm-high spacer ring. Thus, from the start of the mobile plate movement, the flushing syringes begin to draw the dead-volume (i.e., unwanted liquid initially contained in the sampling tube, and in the 3-way valve). After $20 \mathrm{~mm}$ of plate travel, all the dead-volume has been sucked into the flushing syringes, and replaced by water drawn in through the sample inlets. Sampling syringes then start to fill since the mobile plate is now pulling simultaneously on all the syringe extensions.

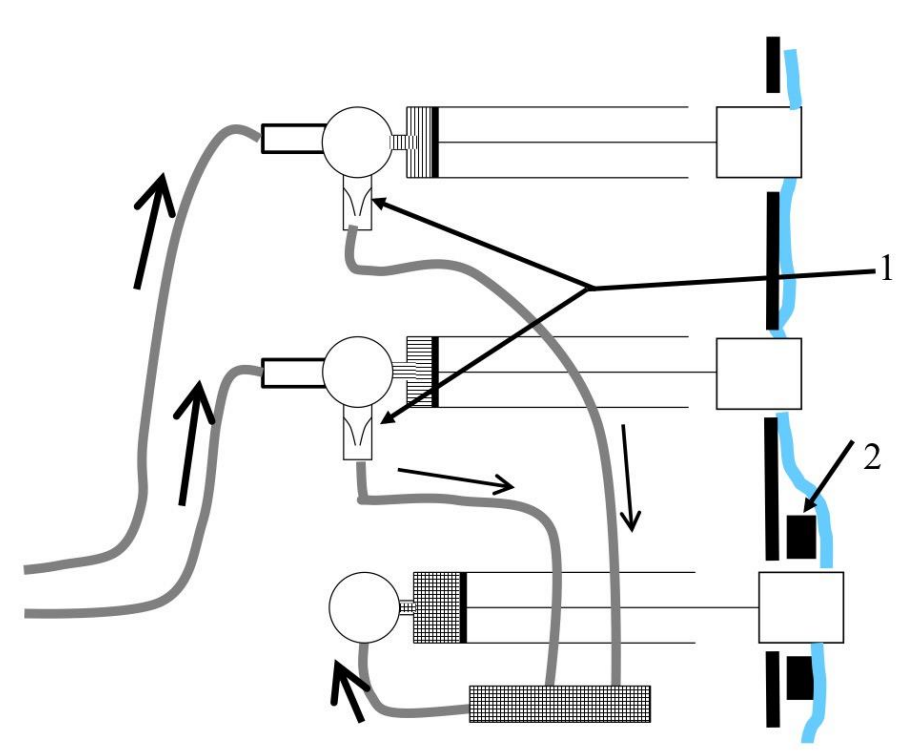

Fig. 4

Fig. 4 : Schematic drawing of the tubing manifold used to flush sample tubes. It shows two sampling syringes filling shortly after the mobile plate starts to pull on their pistons. The top two (sampling) syringes are drawing water through their sample tubing and their 3-way valve, while the bottom syringe (flushing) has filled with dead-volume, and continues filling with sample that has passed through the flushing manifold. Check-valves (1) prevent back-flow from the flushing block into the sampling syringes. The spacer ring (2) for the flushing syringe is 20mm-high 
and circles the piston extension to eliminate the play between mobile plate and the blue polymer rod/lynchpin.

\section{$\underline{\text { Construction materials }}$}

Materials used in the construction of the sampler are polyethylene, PVC, and stainless steel, all chosen for their mechanical properties, corrosion resistance and availability. The stainless steel coil spring was custom made to exert a force ranging from ca. $500 \mathrm{~N}$ to $400 \mathrm{~N}$ in the compressed and extended positions of the jack, respectively. This force is sufficient to overcome friction generated by pulling simultaneously on 20 pistons to fill the syringes in less than one minute. The sampling mast is a PVC pipe and extends $180 \mathrm{~cm}$ upward from the base of the SUSANE. It has been drilled to accommodate and hold the Teflon sampling tubes. The mast is predrilled with labelled holes to be able to reconfigure easily the sampling heights. It is offset from the body of SUSANE, to minimize water disturbance effects on the collected samples, if it is immersed in waters that are not perfectly still. Plastic fairing plates (omitted in Fig. 2) mounted on the vertical sides of the syringe module act as vanes to point the sample inlets upstream of any ambient water-flow, and to protect the syringes while SUSANE is on deck of the boat.

Sample contacts only Teflon tubing, polyethylene barbed fittings, polycarbonate 3-way valves (Cole-Parmer), and the polyethylene and polypropylene of the sampling syringes. All these parts are from Cole-Parmer. We use 60mL, Luer-Lock syringes (Codan, ref 62.8426) with a silicone gasket that remains water-tight after $>10$ dilute acid-cleaning, and repeated uses. 


\section{Procedures for preparation and sampling}

At the laboratory, new Teflon tubing, 3-way valves and syringes are cleaned using isopropyl alcohol rinses, 3-day $0.5 \mathrm{~N} \mathrm{HCl}$ acid soaking, and deionized water rinses, and dried under a laminar flow hood. Once dry, they are stored in closed plastic bags, capped and with their piston drawn to keep the barrel's inner surface and sample inlet free from contamination.

To set up SUSANE, all the syringes are fitted with their valve and piston extension, and locked in place in the stationary plate. They are then connected to the correct sampling and flushing tubes. Immediately before sampling, sample inlets protections are removed, syringe pistons are pushed in; proper positions of the valves, fittings and connectors are verified again. The mobile plate is brought into contact with the stationary one by compressing the coil spring with the cocking screw and crank, and the hinge locked in overextended position. The $20 \mathrm{~mm}$ spacer rings are placed around the extensions of the four flushing syringes and the flexible lynchpin is threaded through all the piston extensions. After an ultimate -- yet indispensable -- verification of the plumbing, SUSANE is brought to its sampling location. When lowered from a small craft to $1 \mathrm{~m}$ above the intended sampling location, one minute is sufficient for the weakest currents to rotate the suspended SUSANE and point its inlets upstream, owing to its lateral fairing vanes. It is then slowly brought down to rest on top of the SWI. An additional 10 minutes equilibration time allows for the settling and/or drifting away of particles that may have been resuspended, and for the dissipation of benthic water-column turbulence due to SUSANE's lowering. The filling of SUSANE is then triggered, the syringes fill in about 45 seconds, after which the sampler can be brought back on board.

To trigger the jack when SUSANE is in place, the back of the hinge is nudged from overextension by the slave rocker, itself actuated by the master rocker lever. An oceanographic messenger's impact on the master rocker can be used, although it requires that the deployment cable is taut, 
and thus that the sampler is positioned vertically under the boat. Also, the bow wave from the messenger's slide along the cable $40 \mathrm{~cm}$ away from the mast may reach the sampling mast and perturb the collected samples since they take time to collect. Fortunately, the lowest sample ports where gradients may be the steepest and most perturbed by the bow wave are protected from this turbulence by the presence of the main body of SUSANE. The second and preferred method to trigger SUSANE uses the simple hydraulic system described above. This method is only limited by the practicality of paying out and spooling both the tubing and cable from a boat. Such configuration is also useful when SUSANE is deployed on the seafloor by a SCUBA diver who can trigger it remotely.

When the spring recoils, it pushes on the mobile PVC plate, immediately starting to fill the flushing syringes. After $20 \mathrm{~mm}$ of motion, the sampling syringe also begin to fill. All the syringes stop drawing sample when the spring's extension is maximal, e.g., the knee-like joint is fully bent. This takes about 45", after which SUSANE can be brought on board for sample processing.

Once on deck, the 3-way valves are closed, isolating samples from the atmosphere. Then, the spring is slightly compressed with the cocking screw to release tension on the syringes, the pin and spacer rings are removed from syringe extensions, and SUSANE can be readied for its next deployment. To do so, it is possible to either remove all the syringes by a twist from their bayonet lock, and by disconnection of the valves from their sample and flush tubes. A second set of syringes, valves and extensions can take their place, thus turning SUSANE around very rapidly. Alternatively, it is also possible to hermetically transfer samples into a second set of syringes fitted with their own 3-way valves, and to process them later at the laboratory. After rinsing the sampling syringes with water from the site, SUSANE can be readied for the next deployment. 
Turnaround-time between two deployments is under one hour and can be managed by a single operator.

\section{Assessment of the sampler}

To validate the proper functioning of SUSANE and its ability to accurately capture vertical concentrations gradients occurring close to the SWI, the following laboratory experiments and field deployments in contrasted environments were conducted.

\section{Laboratory experiments}

Flushing of dead volumes: The Teflon tubing length between a given syringe and its sample inlet ranges 0.5 to $2 \mathrm{~m}$, creating a 0.9 to $3.5 \mathrm{~mL}$ dead-volume which needs to be flushed to improve sample quality. The flushing ability of SUSANE was evaluated as follows. As a worst-case scenario, the inlets of 16 air-filled sampling and 4 flushing tubes were immersed in a large beaker of water and SUSANE was triggered repeatedly. For each triggering, the volume of air drawn into the sampling syringes was always $<0.5 \mathrm{~mL}$, corresponding to the residual dead volume within their 3-way valves and canulae. In the field, the same experiment (trigger SUSANE with sampling tubes initially filled with air) was carried out. Upon recovery, the sampling syringes had 0.1 to $0.3 \mathrm{~mL}$ of air in them, suggesting that the flushing feature operates satisfactorily. Indeed, the flushing syringes draws $56 \mathrm{~mL}$ with every $20 \mathrm{~mm}$ of piston stroke. This volume corresponds to ca. $32 \mathrm{~m}$ of the $1.5 \mathrm{~mm}$ ID sample tubing. Balancing the dead-volume passing through the two flushing manifolds ensures to completely flush all the sample paths at least once before actually drawing liquid into the sampling syringes.

Checking for leaks and cross-sampling: Overall leak-tightness was assessed by closing the 3-way valve of several sampling syringes before triggering the submerged sampler. No water ingress 
was noted in the barrels of the closed syringes, while the other syringes were only partially filled. The absence of mixing between sampling syringes connected to the same flushing block was evaluated by drawing a colored solution into one of the sampling tubes and performing spectrophotometric analyses of the contents of the other syringes. Cross-sampling was not observable. From these experiments, it can be concluded that the tubing manifold distributing samples from inlets to sampling syringes operates in the intended fashion.

Disturbance by bow-wave effects : In order to assess flow disturbances near the sample inlets that would be caused by the presence of SUSANE deployed on a smooth sediment surface, numerical simulation and fluid flow measurements were both conducted at Ifremer's wave and current flume tank facilities. The experimental working section of the tank is $4 \mathrm{~m}$ wide by $2 \mathrm{~m}$ deep and 18m length (Gaurier et al., 2011), so that main flow blockage effect due to the presence of SUSANE and its associated bow wave is not expected. During the experiments, the Susane was resting on a stationary and smooth bottom and submitted to a $0.2 \mathrm{~m} . \mathrm{s}^{-1}$ flow $(\sim 0.4 \mathrm{kn}$, Fig. 5a) with an upstream turbulence intensity rate of $5 \%$. The incoming flow is assumed to be steady and uniform with a $1 / 6^{\text {th }}$ power law vertical velocity profile. While this is the lowest operating flow speed of the tank, the results from the experiments represent a worst-case scenario for flow disturbance, since SUSANE is deployed in waters with typically $<1 / 10^{\text {th }}$ of that flow speed, and hence much less of a bow-wave effect.

The flow regime upstream of the sampling mast of SUSANE (with and without the sampler, Fig. 4b and c) was determined by the use of a 2D Laser Doppler Velocimetry (LDV) that acquires point velocity values $(\mathrm{u}, \mathrm{v})$ in the $\mathrm{X}$ and $\mathrm{Y}$ directions from the mast (Fig. 5b) with a sampling rate of at least $100 \mathrm{~Hz}$ that detects events of $10 \mu \mathrm{m}$ seeding particles (Duran Medina et al., 2017). Automatic displacement tables with a resolution of up to $1 \mathrm{~mm}$ are used to place the LDV 
measurement head at the appropriate positions for velocity profiles in both directions. For the following discussion, the measurement origin $(\mathrm{X}=\mathrm{Y}=\mathrm{Z}=0)$ is set at the lower corner of the sampling module, downstream of the mast.

The influence of the sampler's obstruction on the nearby water flow is experimentally evaluated in Figs. 5c-f, with the comparison of the velocity profiles obtained with and without SUSANE. The vertical depth profiles (Fig. 5c) show that the vertical profile is well conserved with largest flow perturbation occurring within the first $10 \mathrm{~cm}$ above the bottom. It amounts at most to $5 \mathrm{~cm} . \mathrm{s}^{-1}$ $(\sim 25 \%)$ decrease of longitudinal flow, and reaches minimal values above $35 \mathrm{~cm}$ from the bottom (a few $\mathrm{cm} \cdot \mathrm{s}^{-1}$ ). Similarly, longitudinal horizontal profiles acquired $>10 \mathrm{~cm}$ above bottom show that water flow is unimpeded $15 \mathrm{~cm}$ and more upstream of the body of SUSANE (Fig. 5d). The numerical simulations based on the simplified model of Mercier et al. (2017, Fig. 5e-f) are coherent with experimental results. The observations of this "worst-case scenario" for main-flow velocity show that most of the perturbations of the ambient current flow due to the presence of the main body of SUSANE occur at distances less than $0.13 \mathrm{~m}$ from its front edge. Furthermore, some flow perturbation subsists at the current position of the mast (dotted black line, $20 \mathrm{~cm}$ from the main body of SUSANE), as observed experimentally in the flume. 


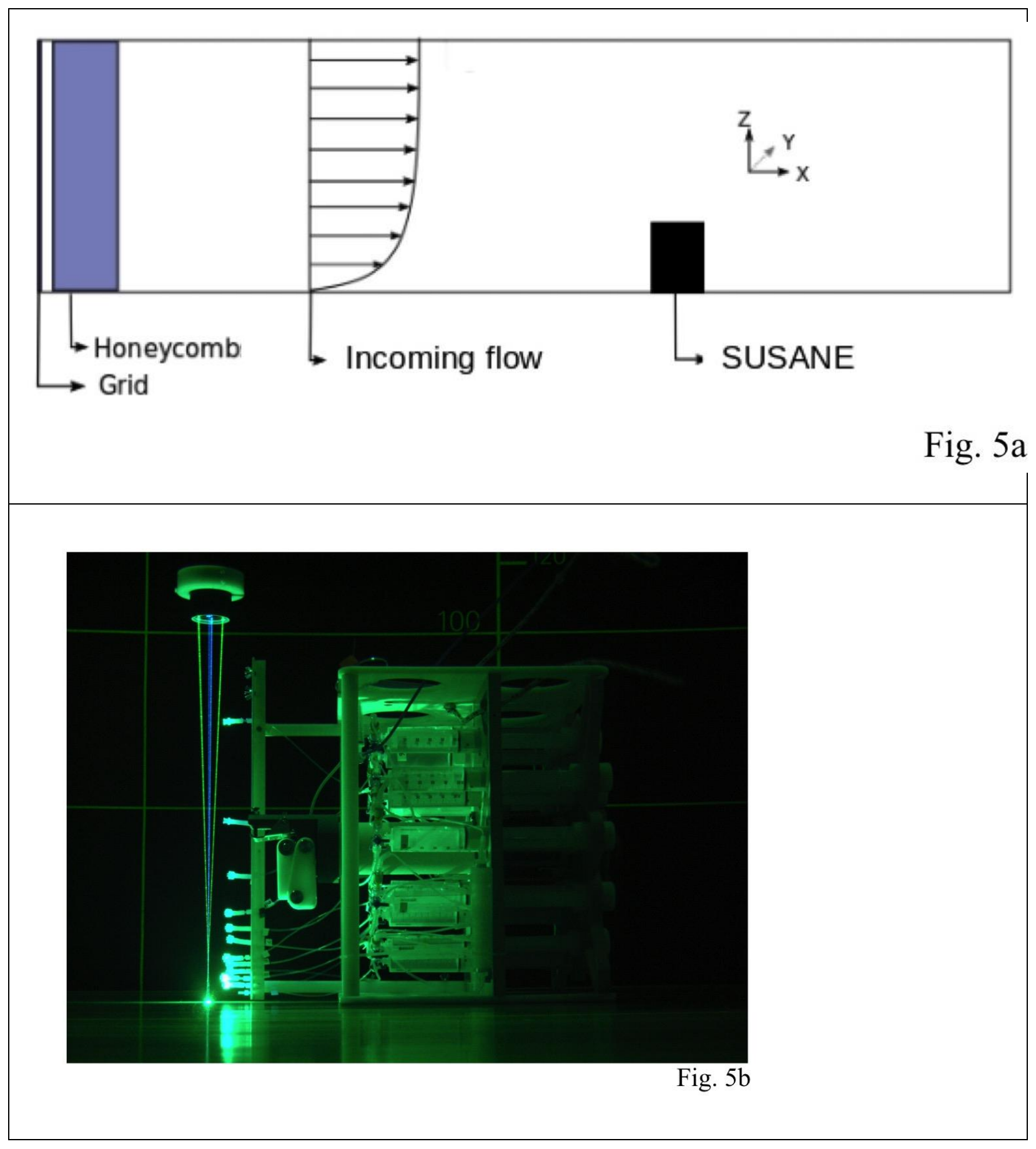




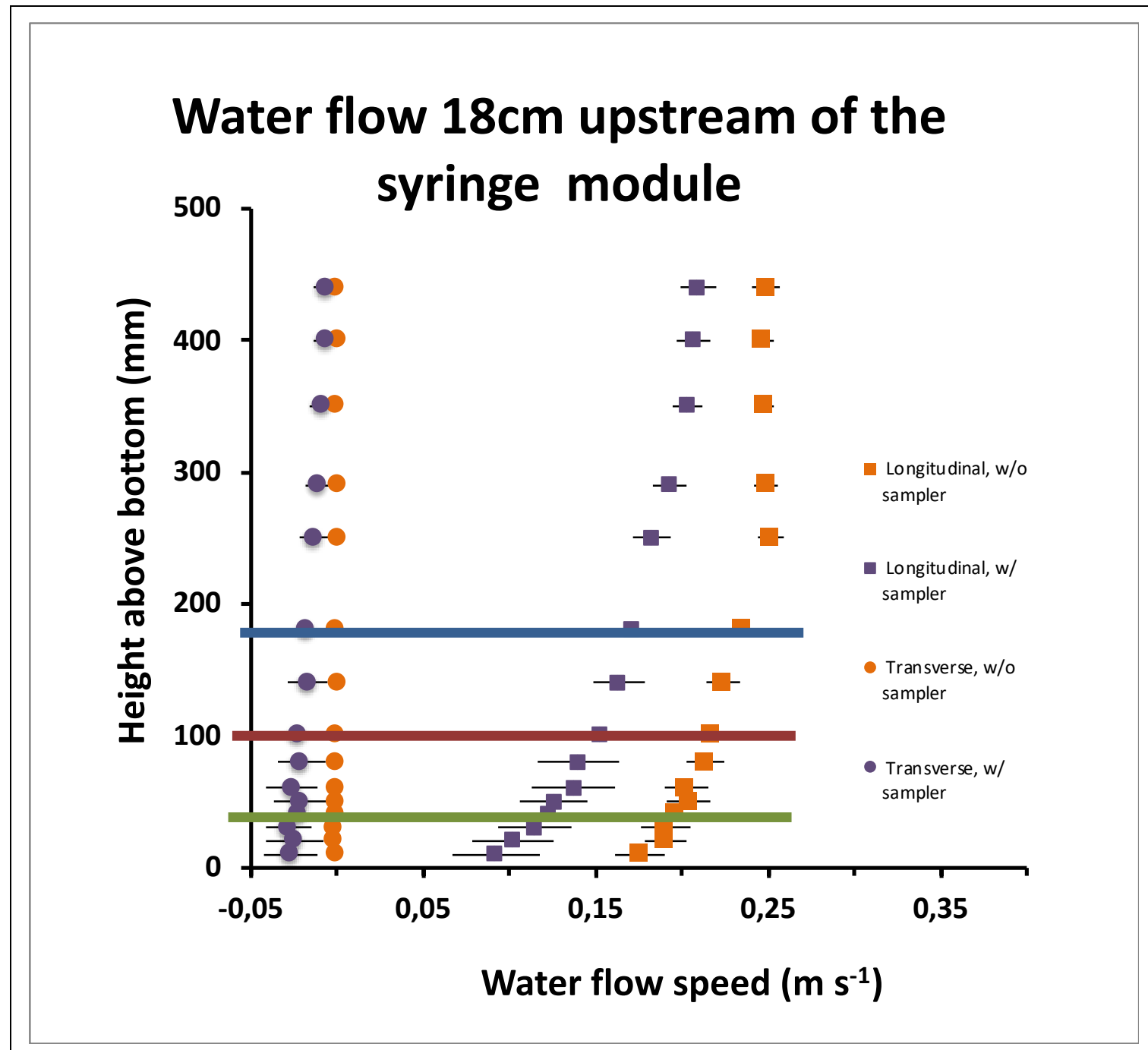

Fig. 5c 


\section{Water flow upstream of sampler}

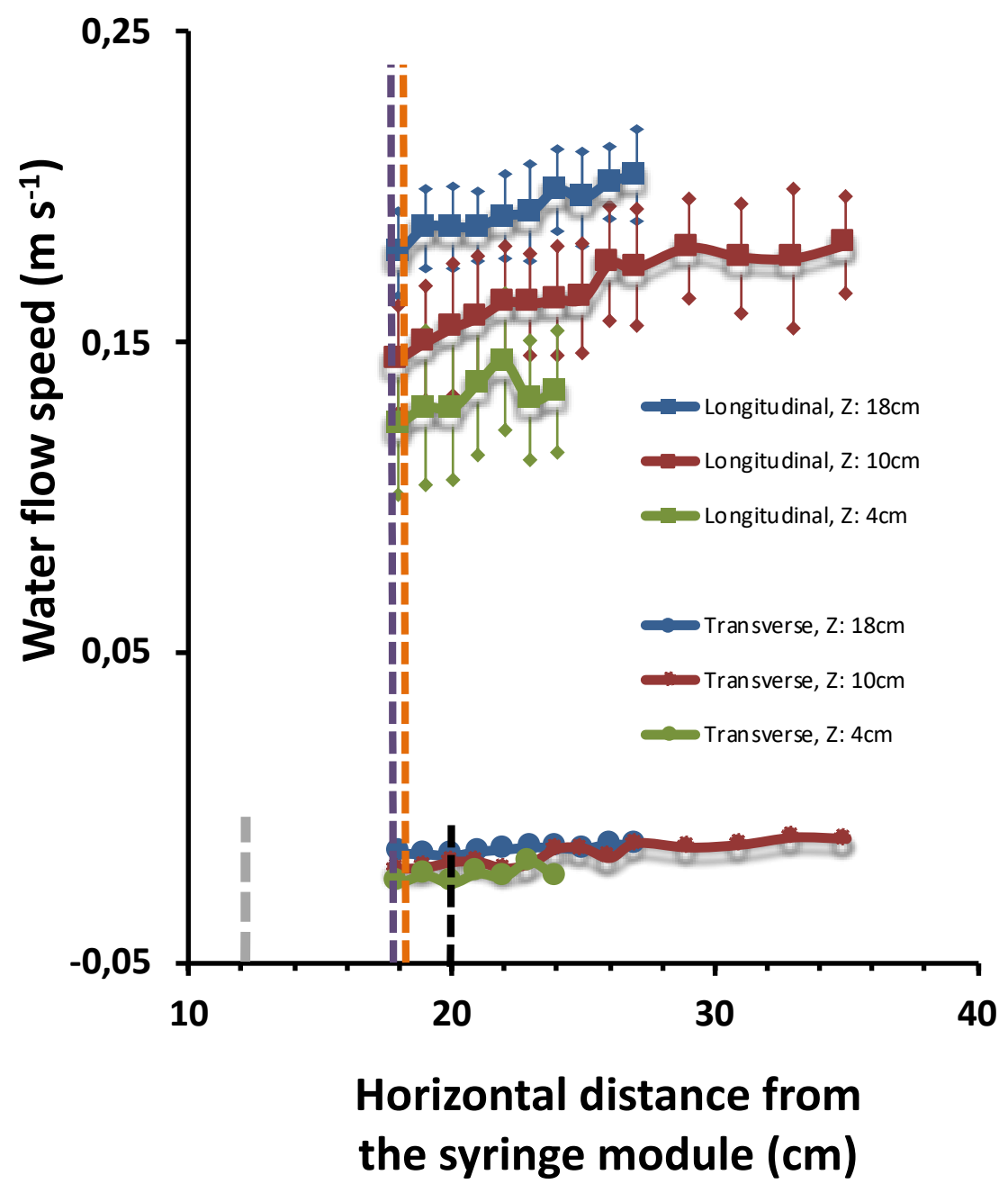

Fig. 5d 


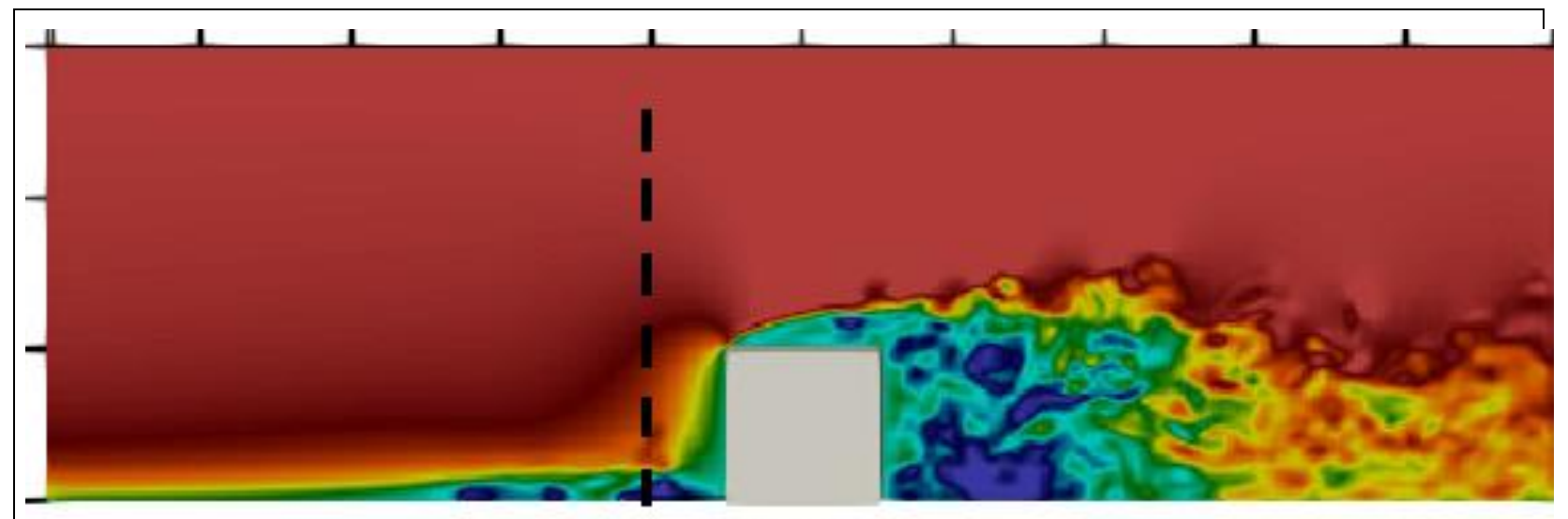

velocity $X$

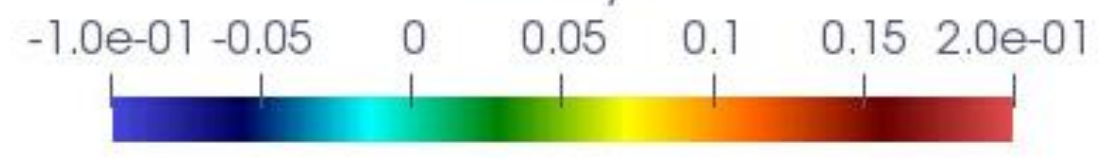

Fig. 5e

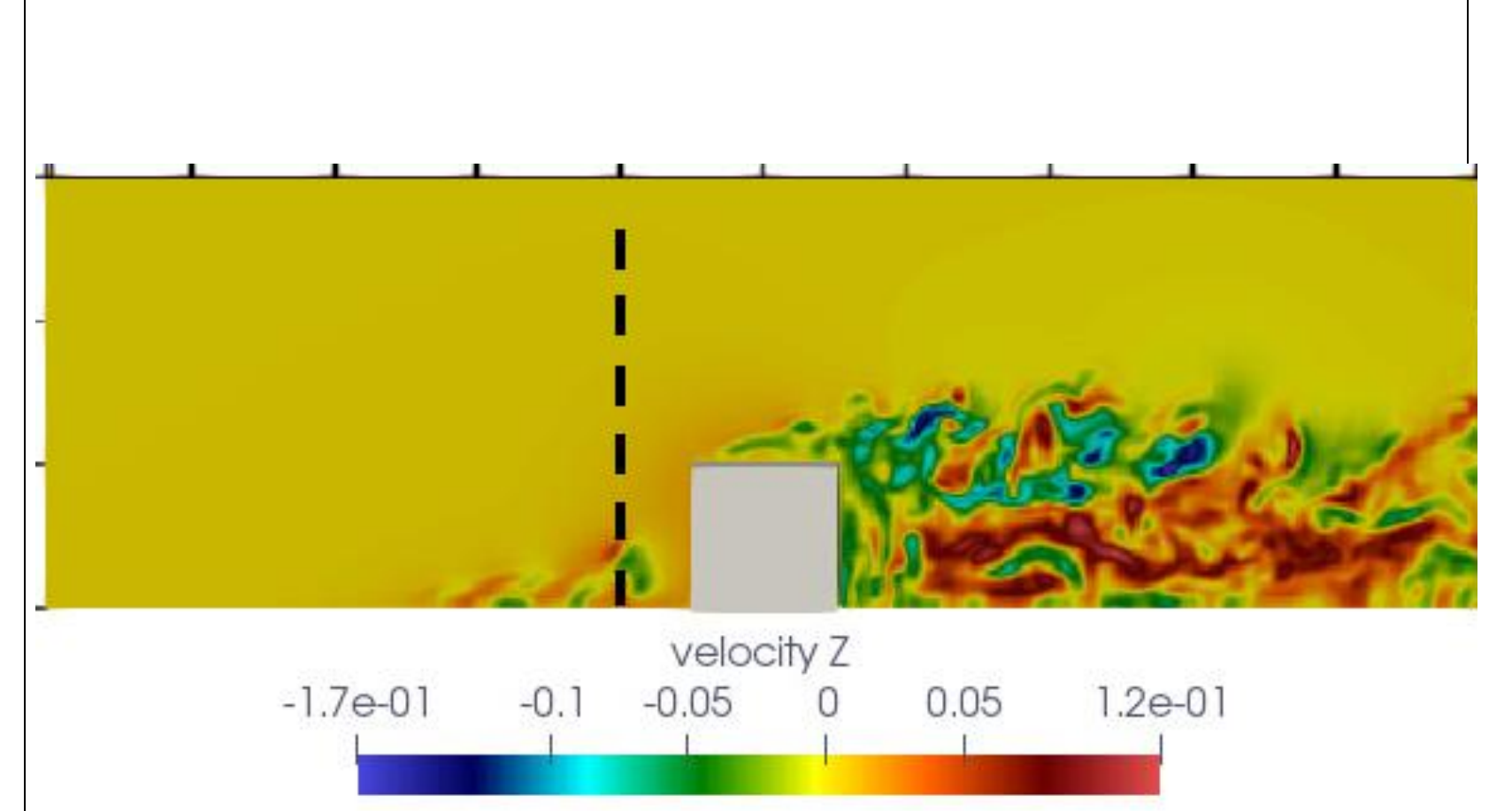

Fig. $5 f$

Fig. 5: Investigations of water flow perturbations by SUSANE in a flume tank.

Panel a : experimental set up in the flume raceway. 
Panel $b$ : SUSANE immersed in the laminar flow flume. Current $\left(0.2 \mathrm{~m} \mathrm{~s}^{-1}\right)$ flows

from left to right. The horizontal velocity of seeding particles is determined at the intersection of the laser beams. The mast pictured here is $12 \mathrm{~cm}$ from the front edge of the sampler. As a result of these flow experiments, the distance betweeen sampling mast and the body of SUSANE was increased to $20 \mathrm{~cm}$.

Panel $c$ : flow velocities observed $18 \mathrm{~cm}$ from the body of the sampler and at different altitudes above the bottom. Longitudinal flow (X-direction) is represented with square symbols, while transverse flow (Y-direction) is represented with circular symbols. Horizontal lines and colors refer to the heights above bottom where the Fig. $5 d$ velocity profiles were collected. Error-bars are the root-mean square of observed flow velocities.

Panel $d$ : flow velocity observed at 4, 10, and $18 \mathrm{~cm}$ above the bottom. Flow velocities in the longitudinal (X-direction, square symbols), and in the transverse (Y-direction, circular symbols) directions at increasing distances upstream of the sampling mast. Colored dotted lines are the positions of the profiles shown in Fig. $5 c$ (orange and purple). Black and grey dotted lines show the sampling mast's current and past positions, respectively.

Panel e: numerical simulation of a "worst-case scenario" where a $20 \mathrm{~cm} . \mathrm{s}^{-1}$ current is obstructed by a representation of SUSANE, modelled as a solid cube with a $40 \mathrm{~cm}$ edge. It shows that the longitudinal flow (i.e., perpendicular to the $Y$-Z plane) is slowed down (units are m.s ${ }^{-1}$ ), when water is both near the bottom (elevation of 1/4 of its edge or less, ca. 0,1m) and near the obstacle (1/3 of its edge, ca. $0.13 \mathrm{~m})$. Furthermore, some flow perturbation subsists at the current position of the mast 
(dotted black line, 20cm from the main body of SUSANE), as observed experimentally in the flume.

Panel f: simulation at the same conditions, but for velocities in the vertical flow (i.e., perpendicular to the $X-Y$ plane), with the scale in $m . s^{-1}$. The vertical velocities are represented here and indicate that vertical water speeds due to the presence of Susane are very low at distances greater than 1/3 of its edge length, and generally much lower than the horizontal velocities.

From the experimental results of this worst-case scenario, we conclude that flow perturbations at the sampling inlets are nil when the mast is offset by $40 \mathrm{~cm}$ from the syringe module. Between ease of handling in the field, required length of sample tubing and associated dead-volume between syringes and sample inlets, and sampling the least-perturbed water column, the compromise is to position the mast $20 \mathrm{~cm}$ away from the main body of SUSANE.

Effects of drawing sample on vertical resolution: SUSANE inherently smooths vertical gradients because its tubing inlets suck in some water from outside their bore. Indeed, drawing $50 \mathrm{~mL}$ in 45 seconds through the open-end of a $1.5 \mathrm{~mm}$ diameter sample inlet likely creates a radial water flow that converges into it. This centripetal flow decreases the gradient by collecting and mixing in the same syringe water from above and below the sample inlet's opening. However, with a main current speed of $1.4 \mathrm{~cm} . \mathrm{s}^{-1}$, a volume of $50 \mathrm{~mL}$ drawn within 45 seconds by one of SUSANE's syringes can pass through an imaginary $1 \mathrm{~cm}$-diameter disc centered on and perpendicular to the inlet. Thus, below that speed and for closest spaced inlets $(1 \mathrm{~cm}$, likely near the SWI), some gradient flattening does occur, inherently to the sampling process. 
The experiments and calculations shown above indicate that the influence of sucking sample into syringes on the characteristics of vertical gradients is largely negligible at nearly all field conditions of sheltered environments, and that near centimeter-scale vertical resolution can be achieved. The possible flattening of steep vertical gradients should however be taken into consideration when interpreting vertical profiles, e.g., to compute benthic fluxes.

\section{Examples of data from contrasted nearshore aquatic environments}

SUSANE was deployed in contrasted marine environments: a shallow bay (Quiberon Bay, Eastern Atlantic ocean) and a coastal lagoon (Berre Lagoon, Northwestern Mediterranean sea). Concentration depth profiles of several substances are shown in figures 6 and 7. The result of their production and consumption processes near the SWI can be seen only with the sampler described here.

Macrotidal and dynamic bay: Bay of Quiberon: The Baie de Quiberon is a macrotidal Bay $\left(150 \mathrm{~km}^{2}, 7 \mathrm{~m}\right.$ mean depth) where the water-column is well mixed and normally oxygenated, according to temperature, salinity and dissolved oxygen measurements from a CTD probe. The SUSANE deployment was carried out in June 2005 in the Western Bay at the site QB4 $47^{\circ} 32.1^{\text {'N }}$ and $03^{\circ} 3.1^{\prime} \mathrm{W}$ during flooding tide at $11 \mathrm{~m}$ depth. At this site, the sediment is mostly sandy mud subjected to wave action (Lemoine, 1989). Sample inlets were positioned at 2, 4, 8, 15, 20, 32, 50, 90 and 180cm above the SWI (Fig. 6). After collection according to the procedures described above, collected samples were kept cool, dark and brought back to the shore laboratory for analyses. They were in-line filtered $(0.45 \mu \mathrm{m}$, cellulose acetate) before being dispensed in the stripping vessel and analyzed for volatile sulfur species, within hours of collection. Dissolved hydrogen sulfide $\left(\mathrm{H}_{2} \mathrm{~S}\right)$, dimethylsulfide (DMS), monomethyl sulfide (MeSH) and carbonyl 
sulfide (COS) were determined by helium sparging extraction and cryogenic trapping in an allTeflon system, followed by semi-capillary gas chromatography separation and pulsed flame photometric detection (Cozic et al., 2008 modified from Radford-Knoery and Cutter 1993). Using this method specifically designed for oxygenated water column work, detection limits are better than $100 \mathrm{pmol} . \mathrm{L}^{-1}$ for these gases, and precision better than $15 \%$.

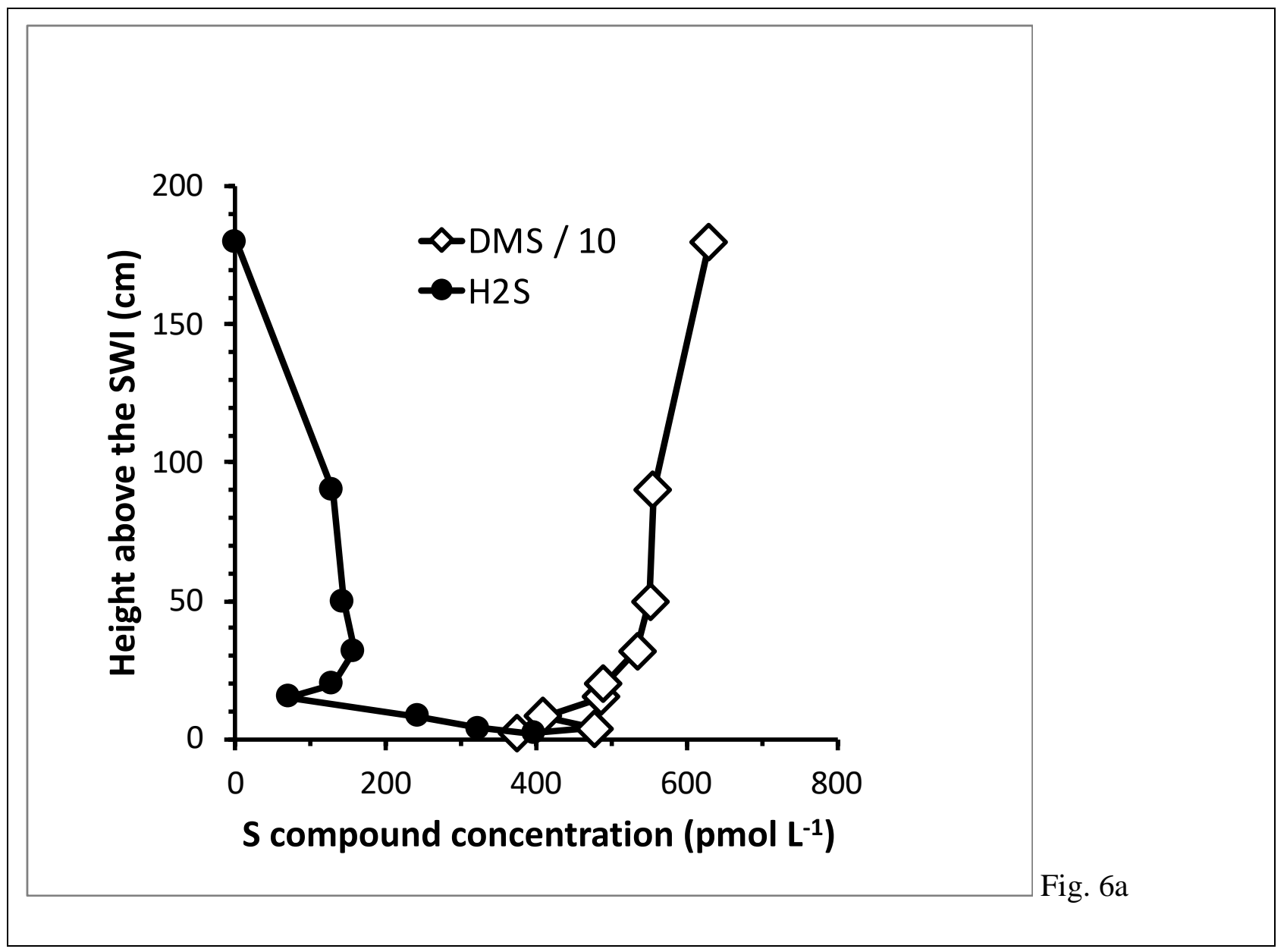




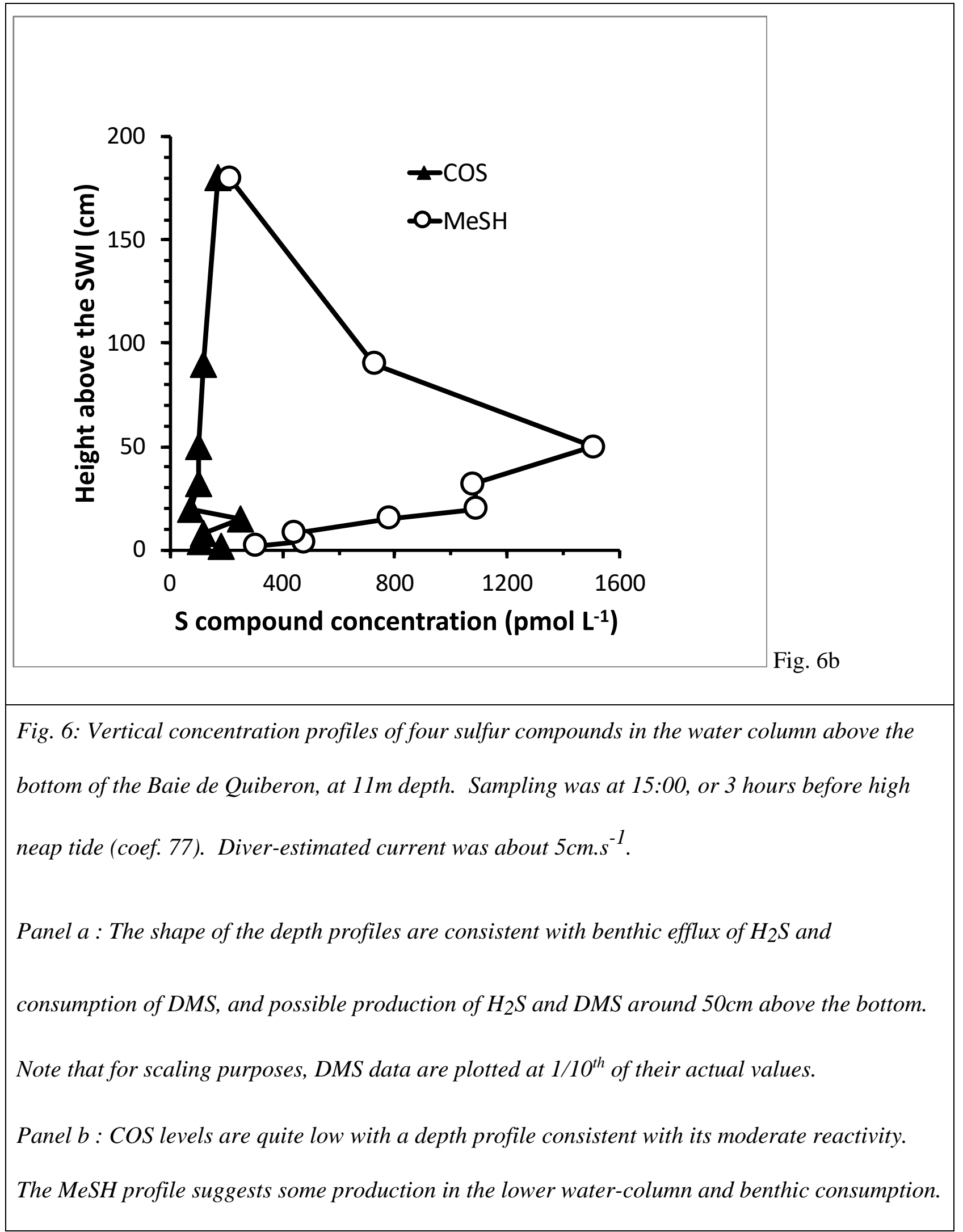

High vertical resolution water sampler 
For the Western Bay of Quiberon site (Fig. 6a), $\mathrm{H}_{2} \mathrm{~S}$ concentrations were non-detectable further than $90 \mathrm{~cm}$ above the SWI, and maximal in close proximity to the sediment. Closer to the SWI, $\mathrm{H}_{2} \mathrm{~S}$ concentrations increased linearly from $0.1 \mathrm{nmol} \cdot \mathrm{L}^{-1}$ at $15 \mathrm{~cm}$ to a maximum of $c a .0 .4 \mathrm{nM}$ observed at $2 \mathrm{~cm}$ above the SWI. Since porewater sulfide levels were undetectable $(<1 \mu \mathrm{M}$ in the topmost $10 \mathrm{~cm}$ of the sedimentary column, methylene blue method), $\mathrm{H}_{2} \mathrm{~S}$ upward diffusion of sulfidic porewaters through the top sediment layer is unlikely. While the presence of nanomolar hydrogen sulfide in oxygenated seawater may still be enigmatic, $\mathrm{H}_{2} \mathrm{~S}$ production in the watercolumn has been argued to occur in oxygen-depleted microenvironments like organic aggregates, zooplankton gut, or fecal pellets (e.g., Tang et al., 2011). Also, it has been shown to be produced by actively growing phytoplankton (Walsh et al., 1994). For DMS, concentrations shown in Fig. 6a increase smoothly from $2-8 \mathrm{~cm}$ above the SWI $\left(4.5 \mathrm{nmol} . \mathrm{L}^{-1}\right)$ to maximum levels (5nmol. $\mathrm{L}^{-1}$ reached at $50 \mathrm{~cm}$ above the SWI). The second panel of Fig. 6 shows that concentrations of COS are rather uniform, and lower than those observed in shelf and estuarine waters (Cutter and Radford-Knoery, 1994). Methane thiol (MeSH) presents a distinctive maximum level of ca. 1.6nmol. $\mathrm{L}^{-1}$ reached at 50cm above the SWI (Fig. 6b). The four reduced sulfur compounds are linked to phytoplankton productivity and decay. The data presented here demonstrate that the water column from a relatively sheltered embayment, even if under tidal influence, is clearly not homogeneous near the SWI.

Microtidal Mediterranean lagoon: The Berre Lagoon is $175 \mathrm{~km}^{2}$ and $6 \mathrm{~m}$-deep Mediterranean lagoon, that is both eutrophicated, impacted by hypoxia-anoxia events, and presents contaminated sediment due to the industrialization of its shores (Rigaud et al., 2011). SUSANE deployments were carried out in July and August 2009 near the center of the Berre Lagoon at $43^{\circ} 26.538^{\prime} \mathrm{N}$ 
and $05^{\circ} 05.839^{\prime} \mathrm{E}$ at $9 \mathrm{~m}$ depth. In this area, sediment is silty clay loam. In July 2009 , bottom water was hypoxic (dissolved $\mathrm{O}_{2}$ concentration $=15-20 \mu \mathrm{M},<10 \% \mathrm{O}_{2}$ saturation). The oxygen concentrations kept decreasing over the following weeks to reach complete anoxia in August $2009\left(\mathrm{O}_{2}=0 \mu \mathrm{M}, 0 \% \mathrm{O}_{2}\right.$ saturation) (Rigaud et al., 2013). SuSANE was deployed with only twelve syringes and their inlets positioned at $1,2,3,4,5,6,8,10,12.5,17.5,25$, and $40 \mathrm{~cm}$ above the SWI. Note that in July 2009, the lowest syringe appeared filled with sediment indicating that the SUSANE device sank by more than one but less than two centimeters into the sediment during the deployment. The actual elevation of the inlets above the sediment was repositioned accordingly for data reporting. After deployment, SUSANE was brought back to a shore laboratory where water samples were filtered using $0.2 \mu \mathrm{m}$ cellulose acetate syringe filters and split according to the type of analysis to be performed. Total $\mathrm{CO}_{2}\left(\mathrm{tCO}_{2}=\mathrm{CO}_{2}+\mathrm{HCO}_{3}{ }^{-}+\mathrm{CO}_{3}{ }^{2-}\right)$ and $\mathrm{NH}_{4}{ }^{+}$ concentrations were measured by flow injection analysis (FIA) following the methods developed by Hall and Aller (1992). $\sum \mathrm{H}_{2} \mathrm{~S}$ and $\sum \mathrm{PO}_{4}$ concentrations were performed using spectrophotometry following Metzger et al. (2007). FIA and spectrophotometric analysis accuracies were $\sim 10 \%$. Water samples were analyzed notably for Fe, Mn, and As using ICP-MS (Agilent 7700x equipped with HMI kit). The accuracies were checked using a seawater reference NASS-4 (NRCC) enriched with trace elements to achieve concentration ranges similar to the samples. The accuracies of the measurements were within $5 \%$ for Fe, Mn, and $10 \%$ for As. Total dissolved $\mathrm{Hg}$ (Hgtot) concentrations were determined using cold vapor atomic fluorescence spectrometry (CVFAS, Tekran) following the EPA-1631 method (EPA, 2002). The accuracies were confirmed using the reference material ORMS-4 (NRCC) and were approximately 5\%. The analysis of dissolved $\mathrm{MeHg}$ was performed using atomic fluorescence spectrophotometry following the protocol developed by Tseng et al. (1998). Dissolved organic carbon (DOC) 
concentrations were determined on a TOC-V CHS analyzer, Shimadzu. In Fig. 7, depth profiles of 10 different chemical species show that the difference oxygen saturation clearly impacts their vertical distribution. Under hypoxic conditions, benthic layer water samples were characterized by non-detectable $\sum \mathrm{H}_{2} \mathrm{~S}$ and relatively low concentrations of $\sum \mathrm{PO}_{4}, \mathrm{NH}_{4}$ and trace elements except at the lowest $2-3 \mathrm{~cm}$ above the SWI, where steep gradients were observed. These steep gradients indicate that remobilization/production processes are occurring at the SWI for most of the chemical species which are rapidly introduced to the water column. There, they are then diluted in the overlying water mass and/or then re-oxidized. Under anoxic conditions, the concentrations of $\mathrm{tCO}_{2}, \sum \mathrm{H}_{2} \mathrm{~S}, \sum \mathrm{PO}_{4}, \mathrm{NH}_{4}{ }^{+}, \mathrm{DOC}, \mathrm{As}, \mathrm{Hg}_{\text {tot }}$ and $\mathrm{MeHg}$ were highest close to the SWI and linearly decreased with distance from the SWI. This also suggests releases from the sediment to the water column, but in that case, that their dilution and/or re-oxidation processes in the water column are slower. This is expected with the absence of oxygen, which allows the increase in concentration of these species in the benthic zone. Interestingly, under anoxic conditions Fe and Mn profiles contrast with the other chemical species. Indeed, their concentrations both tend to decrease at the SWI suggesting that scavenging processes do occur there. Such patterns could be due to increased Fe-sulfide and Mn-carbonate precipitation in the sediment, as shown in this site from a porewater profile modeling approach (Rigaud et al., 2013). The sampler presented here is the first device that is able to acquire water-column samples to test and validate this hypothesis. 


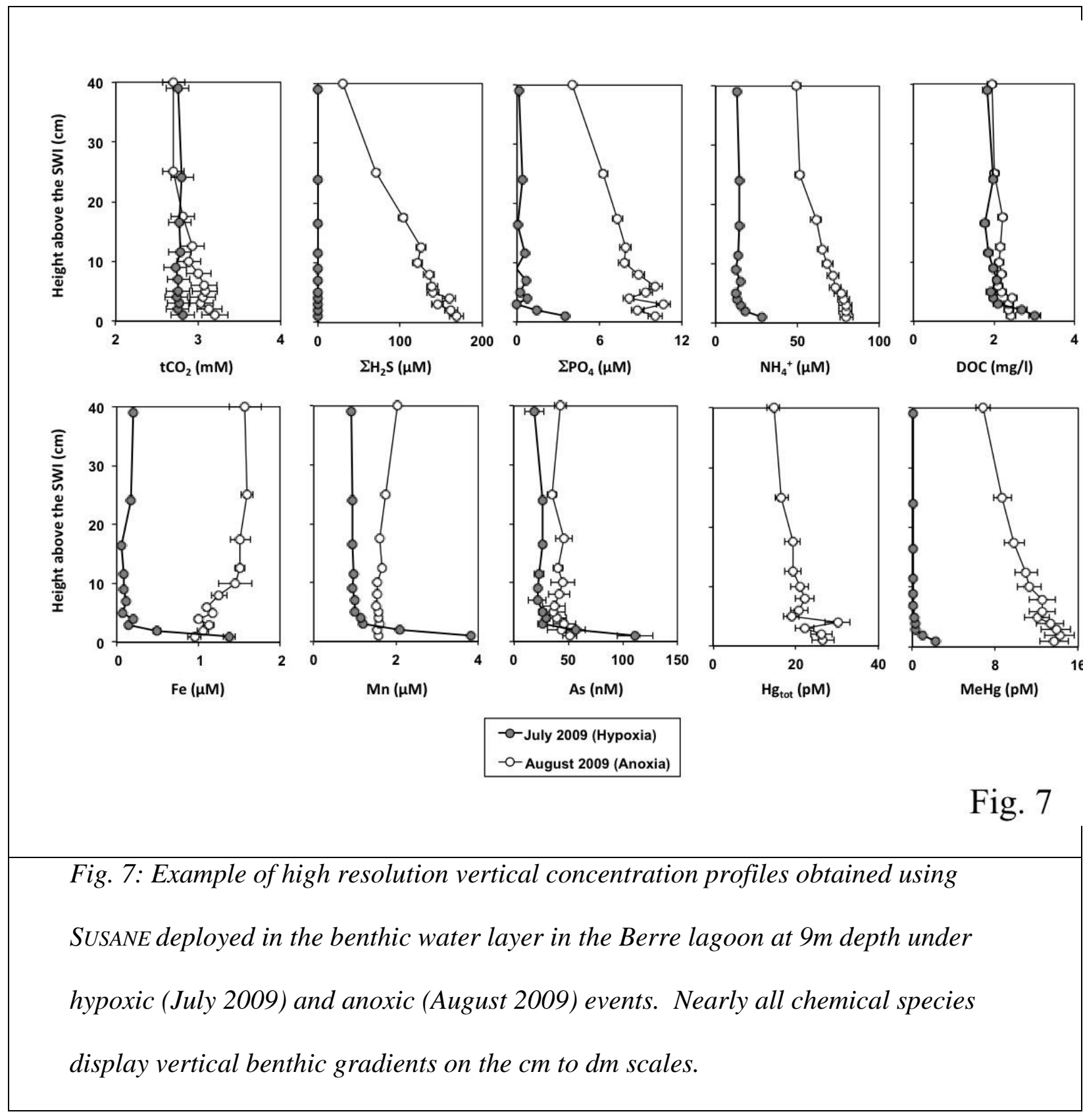

\section{Comments and recommendations}

The benthic sampler for nearshore environments (SUSANE) is easy to use and a yet relatively inexpensive addition to the array of water sampling tools used by aquatic scientists. It allows the user to collect simultaneously and at high resolution discrete samples that are suitable for major and trace species analyses, even within the first decimeter above the sediment-water interface, 
where concentration gradients have been shown to occur. The presence of these gradients above the diffusive boundary layer, despite the turbulent mixing in the benthic water-column, is evidence of processes affecting these substances that occur at the SWI and in the lower watercolumn. To quantify the these biogeochemical processes, i) adequate chemical characterization of these gradients is necessary, as well as ii) the complimentary knowledge of the hydrodynamics of the benthic layer like the intensity of turbulent mixing. While more chemical and physical data is needed to explore the examples given here, we have shown that discrete samples from the benthic water layer can provide biogeochemical data that were previously unattainable. This ability may contribute to better description and exploration of sediment-water interactions.

Thus, coupled with benthic hydrodynamics, this device will help to bridge the gap between different methods used to determine solute fluxes at the sediment-water interface. Indeed, measured or modeled vertical velocity structures (e.g., Hondzo et al., 2005) with the help of actual observations of chemical vertical gradients near the SWI acquired with SUSANE may enable the direct determination of chemical fluxes between sediment and water column (Holtappels, 2011). This approach will have the advantage to be direct, to integrate vertical exchanges at a large spatial scale, and to be relatively independent of the nature of the substratum. In addition, SUSANE can be adapted to describe solute concentrations with different spatial configurations, e.g, to match sediment surface lateral heterogeneity. Indeed, the current vertical and linear disposition of sampling ports may be changed into a $2 \mathrm{D}$ array. Furthermore when the required sample volumes exceed $50 \mathrm{~mL}$, the tube network ports can easily be reconfigured to connect one sampling port to several syringes. Finally, there is no depth limitation to using SUSANE as it is entirely constructed of solid materials. 


\section{$\underline{\text { References }}$}

Bale, A. J. and Barrett C. D. 1995. A bottom-landing water sampling system for the benthic boundary layer. Neth. J. Sea Res. 34:259-266.

Berner, R. A. 1980 Early diagenesis - a theoretical approach. Princeton University Press Cozic, A., Viollier E., Chiffoleau J.-F., Knoery J., Rozuel E. 2008. Interactions between Volatile Reduced Sulfur Compounds and Metals in the Seine Estuary (France). Estuaries and Coasts 31:1063-1071.

Cutter G.A. et Radford-Knoery J., 1994. Carbonyl sulfide in two estuaries et shelf waters of the western North Atlantic Ocean. Mar. Chem, 43 : 225-233.

Dade, B. D., A. Hogg, and B. P. Boudreau. 2001. Physics of flow above the sedimentwater interface, p. 4-43. In B. P. Boudreau and B. B. Jørgensen [eds.], The benthic boundary layer: transport processes and biogeochemistry. Oxford Univ. Press.

Duran Medina O., F.G. Schmitt, R. Califff, G. Germain, B. Gaurier., 2017 Turbulence analysis and multiscale correlations between synchronised flow velocity and marine turbine power production, Renewable Energy 12:314:327 https://doi.org/10.1016/j.renene.2017.05.024

EPA Method 1631, Revision E: Mercury in water by oxidation, purge and trap, and cold vapor atomic fluorescence spectrometry; U.S. Environmental Protection Agency: Washington DC, 2002. https://www.epa.gov/sites/production/files/201508/documents/method_1631e_2002.pdf

B. Gaurier, G. Germain, Y. Kervella, J. Davourie, F. Cayocca, P. Lesueur, 2011 Experimental and numerical characterisation of the impact of an oyster table on the 
flow, European Journal of Mechanics - B/Fluids, 30:513-525

https://doi.org/10.1016/j.euromechflu.2011.05.001

Glud, R.N., 2008. Oxygen dynamics of marine sediments. Mar. Biol. Res. 4 (4), 243289

Hall P. O. J., R.C. Aller, 1992 Rapid, small-volume, flow injection analysis for $\sum \mathrm{CO}_{2}$ and NH4+ in marine and freshwaters Limnol. Oceanogr., 37:1113-1119

Holtappels, M., Kuypers, M. M. M., Schlüter M., and Volker Brüchert V. 2011. Measurement and interpretation of solute concentration gradients in the benthic boundary layer. Limnol. Oceanogr. Methods 9: 1-13.

Hondzo, M., Feyaerts T., Donovan R. and O'Connor B. L., 2005. Universal scaling of dissolved oxygen distribution at the sediment-water interface: A power law. Limnol. Oceanogr. 50:1667-1676.

Ikhennicheu M., P. Druault, B. Gaurier, G. Germain, 2018. Experimental analysis of the floor inclination effect on the turbulent wake developping behind a wall-mounted cube. European Journal of Mechanics/B Fluids 72: 340-352 https://doi.org/10.1016/j.euromechflu.2018.07.003 Lemoine, G. 1989. Etude sédimentaire de la baie de Quiberon : La zone ostréicole en eau profonde et ses abords. Rapport Ifremer - La Trinité-sur-Mer, France, 102pp. http://archimer.ifremer.fr/doc/00000/2210/

Mercier P, M. Grondeau, S. Guillou, E. Thiebot. and E. Poizot., 2017. Toward the modelling of turbulence at tidal stream power sites with the Lattice Boltzmann Method. Paper presented at the 2017 EWETEC conference (8pp). 
Metzger E., C. Simonucci, E. Viollier, G. Sarazin, F. Prévot, D. Jézéquel, 2007.

Benthic response to shellfish farming in Thau lagoon: pore water signature Estuar. Coast Shelf Sci.,72:406-419

Pakhomova, S., E. V. Yakushev, E. Protsenko, S. Rigaud, D. Cossa, J. Knoery, R. M. Couture, O. Radakovitch, S. Yakubov, D. Krzeminska, and A. Newton. 2018 Modelling the influence of eutrophication and redox conditions on mercury cycling at the sediment-water interface in the Berre Lagoon. Front. Mar. Sci. | doi: 10.3389/fmars.2018.00291.

Radford-Knoery, J. and Cutter G. A., 1993 Determination of carbonyl sulfide and hydrogen -sulfide species in natureal waters using specialized collection procedures and gas chromatography with flame photometric detection. Analytical Chemistry 65:976982.

Radford-Knoery, J. and Cutter G. A., 1994. Biogeochemistry of dissolved hydrogen sulfide species and carbonyl sulfide in the western north Atlantic ocean. Geochim. Cosmochim. Acta 58:5421-5431.

Rigaud S., O. Radakovitch, D. Nerini, P. Picon, J.M. Garnier, 2011 Reconstructing historical trends of Berre lagoon contamination from surface sediment datasets: Influences of industrial regulations and anthropogenic silt inputs. J. Environmental Management 92:2201-2210 doi:10.1016/j.jenvman.2011.04.002

Rigaud S., O. Radakovitch, R.-M. Couture, B. Deflandre, D. Cossa, C. Garnier, J.-M. Garnier, 2013 Mobility and fluxes of trace elements and nutrients at the sediment-water interface of a lagoon under contrasting water column oxygenation conditions, Applied Geochemistry 31:35-51 doi.org/10.1016/j.apgeochem.2012.12.003. 
Sauter, E. J., Schluter M., Wegner J., and Labahn E., 2005. A routine device for high resolution bottom water sampling. J. Sea Res. 54:204-210.

[doi:10.1016/j.seares.2005.04.005].

Schulz, H. D. 2000. Quantification of early diagenisis: dissolved constituents in marine pore water, p. 85-128. In H. D. Schulz and M. Zabel [eds.], Marine geochemistry. Springer.

Tang, K. W., Glud R. N., Glud A., Rysgaard S., Nielsen T. G. ,2011 Copepod guts as biogeochemical hotspots in the sea: Evidence from microelectrode profiling of Calanus spp. Limnology and Oceanography 56:666-672 doi:10.4319/lo.2011.56.2.0666

Thomsen, L., Graf G., Martens V. and Steen E., 1994. An instrument for sampling water from the benthic boundary layer. Cont. Shelf Res. 14:871-882.

Tseng C. M., A. de Diego, H. Pinaly, D. Amouroux and O. F. X. Donard, 1998 Cryofocusing coupled to atomic absorption spectrometry for rapid and simple mercury speciation in environmental matrices Journal of Analytical Atomic Spectrometry $13: 755-764$

Walsh, R. S., Cutter G. A., Dunstan W. M., Radford-Knoery J. and Elder J. T., 1994. The biogeochemistry of hydrogen sulfide: Phytoplankton production in the surface ocean. Limnol. Oceanogr. 39:941-948. 


\section{Acknowledgments}

We gratefully acknowledge funding from the EU (FP7- GMOS), from the region Pays de la Loire (PolluSols), the region Provence-Alpes-Côte-d'Azur, and from the GIPREB. Financial support was also provided by the BERTOX project awarded by INSU-EC2CO to O. Radakovitch. We thank the reviewers for their thoughtful, detailed and constructive reviews that helped to improve the manuscript.

\section{Conflict of interest}

No potential conflict of interest exists. 
Figure legends

Fig. 1 : Conceptual drawing of SUSANE showing the bottom part of the sampling mast and the syringe module. It illustrates the mechanical links between the trigger rocking levers, the telescopic jack, and the syringes. As shown, three sampling syringes ( $\mathrm{Sa}$ ) are connected by Teflon tubes to their own sample inlets on the mast, and have piston extensions (Ex) that protrudes through the mobile plate (Mo). They are threaded by a flexible rod that acts as a lynchpin, locking together the Mo and the syringe pistons. A single flushing syringe $(\mathrm{Fl})$ is shown with the spacer ring. Syringe barrels and pistons are connected to the stationary (St) and mobile (Mo) PVC plates, themselves placed at each end of the spring-loaded, telescopic jack (Ja).

Numbered items are (1): Master lever; (2): Bowden cable for master to slave rocker lever transmission; (3): Slave rocker that can push lightly at the back of the "knee-like" hinge; (4): Knee-like hinge that locks when overextended in its open position; (5): Smooth stainless steel rod connecting the distal end of the hinge and the mobile plate. It pulls on the mobile plate and compresses the spring when in the hinge is extended; (6): Sampling mast supporting the sampling tube inlets at their chosen positions; (7): Example of three sampling tube inlets at the base of the mast. The flushing manifold is omitted for clarity; (8): 20mm high spacer ring to take up the play between lynchpin and mobile plate; (9): flexible polymer rod threaded through all the piston extensions.

Fig. 2 : Detailed photographs of the sampler

Panels a, b, c : Side and rear photographs of the SUSANE in its tripped position (i.e., bent hinge). To show the inner workings of SUSANE, its two fairing plates that act as vanes have been removed from the sides of the device (panels a and c). Except for the hinge and its sampling 
mast which is $180 \mathrm{~cm}$ high and offset from its main body by $20 \mathrm{~cm}$, SUSANE main body's dimensions shown in Panel (a) are 40 x 40 x 40cm.

Panel a: (1): Filled sampling syringe; (2): its 3-way valve ; (3): flushing manifold; (4): flushing tubing along a sampling syringe; (5): check-valve.

Panel b: (6): for scale and to illustrate the sampling resolution of Susane, the lowest sample inlets in the vertical mast are $10 \mathrm{~mm}$ apart. The vertical resolution can be adjusted in the field by moving the sampling tubes to other pre-drilled positions elsewhere on the mast. In the picture, the mast is offset by $20 \mathrm{~cm}$ from the lower edge of syringe module.

Panel c: three black spacer rings around extensions of the flushing syringes pistons are visible, the cocking screw and its removable crank are used to compress the spring inside the jack, the blue polymer rod threaded through the extensions, and the red-tipped master rocker lever on the top of SUSANE.

Panel d: (7): Bowden cable linking master and slave rockers; (8): 20meters of water-filled, semi rigid tubing coiled and terminated by the master and slave syringes; (9): slave syringe whose piston extends upward to actuate the master rocker, when the piston of the master syringe (10) is pushed in by the operator.

Fig. 3: Schematic of the telescopic jack functioning in SUSANE before and after triggering. Top panel: the jack is in a cocked position and ready to be tripped. (1) Knee joint-like hinge in its overextended, locked position. Rotation of slave rocker (2) pushes its left end on the "back" of the knee-joint, decreasing its angle to less than $180^{\circ}$, at which point the force of the coil spring (3) finishes to bend the knee-like hinge. Bottom panel: the hinge has bent and allowed the smooth stainless steel rod to move rightward, and the jack to extend, thus pushing the mobile plate (Mo) apart from its stationary counterpart $(\mathrm{St})$. 
Fig. 4 : Schematic drawing of the tubing manifold used to flush sample tubes. It shows two sampling syringes filling shortly after the mobile plate starts to pull on their pistons. The top two (sampling) syringes are drawing water through their sample tubing and their 3-way valve, while the bottom syringe (flushing) has filled with dead-volume, and continues filling with sample that has passed through the flushing manifold. Check-valves (1) prevent back-flow from the flushing block into the sampling syringes. The spacer ring (2) for the flushing syringe is $20 \mathrm{~mm}$-high and circles the piston extension. It takes up all the play between mobile plate and the blue polymer rod/lynchpin.

Fig. 5: Investigations of water flow perturbations by SUSANE in a flume tank.

Panel a : experimental set up in the flume raceway.

Panel b : SuSANE immersed in the laminar flow flume. Current (0.2m.s-1) flows from left to right. The horizontal velocity of seeding particles is determined at the intersection of the laser beams. The mast pictured here is $12 \mathrm{~cm}$ from the front edge of the sampler. As a result of these flow experiments, the distance between sampling mast and the body of SUSANE was increased to $20 \mathrm{~cm}$.

Panel c : flow velocities observed $18 \mathrm{~cm}$ from the body of the sampler and at different altitudes above the bottom. Longitudinal flow (X-direction) is represented with square symbols, while transverse flow (Y-direction) is represented with circular symbols. Horizontal lines and colors refer to the heights above bottom where the Fig. 5d velocity profiles were collected. Error-bars are the root-mean square of observed flow velocities.

Panel d : flow velocity observed at 4,10 , and $18 \mathrm{~cm}$ above the bottom. Flow velocities in the longitudinal (X-direction, square symbols), and in the transverse (Y-direction, circular symbols) directions at increasing distances upstream of the sampling mast. Colored dotted lines are the 
positions of the profiles shown in Fig. 5c (orange and purple). Black and grey dotted lines show the sampling mast's current and past positions, respectively.

Panel e: In the X-Z plane, a numerical simulation of a "worst-case scenario" where a $20 \mathrm{~cm} . \mathrm{s}-$ 1current is obstructed by a representation of SUSANE, modelled as a solid cube with a $40 \mathrm{~cm}$ edge. It shows that the longitudinal flow is slowed down, when water is both near the bottom (elevation of $1 / 4$ of its edge or less, ca. $0.1 \mathrm{~m})$ and near the obstacle (1/3 of its edge, ca. $0.13 \mathrm{~m})$. Furthermore, some flow perturbation subsists at the current position of the mast (dotted black line, $20 \mathrm{~cm}$ from the main body of SUSANE), as observed experimentally in the flume. Panel f: simulation at the same conditions, but in the horizontal (X-Y) plane. The vertical velocities are represented here and indicate that vertical current speeds due to the presence of Susane are very low at distances greater than $1 / 3$ of its edge length.

Fig. 6: Vertical concentration profiles of four sulfur compounds in the water column above the bottom of the Baie de Quiberon, at 11m depth. Sampling was at 15:00, or 3 hours before high neap tide (coef. 77). The diver estimated current at about $5 \mathrm{~cm} . \mathrm{s}^{-1}$.

Panel a : The shape of the depth profiles are consistent with benthic efflux of $\mathrm{H}_{2} \mathrm{~S}$ and consumption of DMS, and possible production of $\mathrm{H}_{2} \mathrm{~S}$ and DMS around $50 \mathrm{~cm}$ above the bottom.

For plotting scale purposes, note that DMS data are plotted at $1 / 10^{\text {th }}$ of their actual values.

Panel b : COS levels are quite low with a depth profile consistent with its moderate reactivity. The MeSH profile suggests some production in the lower water-column and benthic consumption. 
Figure 7: Example of high resolution vertical concentration profiles obtained using SUSANE deployed in the benthic water layer in the Berre lagoon at 9m depth under hypoxic (July 2009) and anoxic (August 2009) events. Nearly all chemical species display vertical benthic gradients on the $\mathrm{cm}$ to $\mathrm{dm}$ scales. 